Article

\title{
Asphalt Incorporation with Ethylene Vinyl Acetate (EVA) Copolymer and Natural Rubber (NR) Thermoplastic Vulcanizates (TPVs): Effects of TPV Gel Content on Physical and Rheological Properties
}

\author{
Nappaphan Kunanusont ${ }^{1}\left(\mathbb{D}\right.$, Boonchai Sangpetngam ${ }^{2}$ and Anongnat Somwangthanaroj ${ }^{1,3, *(\mathbb{D})}$ \\ 1 Department of Chemical Engineering, Faculty of Engineering, Chulalongkorn University, \\ Bangkok 10330, Thailand; mai2newwood@hotmail.com \\ 2 Department of Civil Engineering, Faculty of Engineering, Chulalongkorn University, \\ Bangkok 10330, Thailand; boonchai.sa@chula.ac.th \\ 3 Bio-Circular-Green Economy Technology \& Engineering Center, BCGeTEC, Faculty of Engineering, \\ Chulalongkorn University, Bangkok 10330, Thailand \\ * Correspondence: anongnat.s@chula.ac.th
}

Citation: Kunanusont, N.; Sangpetngam, B.; Somwangthanaroj, A. Asphalt Incorporation with Ethylene Vinyl Acetate (EVA) Copolymer and Natural Rubber (NR) Thermoplastic Vulcanizates (TPVs): Effects of TPV Gel Content on Physical and Rheological Properties. Polymers 2021, 13, 1397. https:// doi.org/10.3390/polym13091397

Academic Editors: Elnaz Esmizadeh and Ali Vahidifar

Received: 28 February 2021

Accepted: 22 April 2021

Published: 26 April 2021

Publisher's Note: MDPI stays neutra with regard to jurisdictional claims in published maps and institutional affiliations.

Copyright: (c) 2021 by the authors. Licensee MDPI, Basel, Switzerland. This article is an open access article distributed under the terms and conditions of the Creative Commons Attribution (CC BY) license (https:/ creativecommons.org/licenses/by/ $4.0 /)$.

\begin{abstract}
Plastic waste has been incorporated with asphalt to improve the physical properties of asphalt and alleviate the increasing trend of plastic waste being introduced into the environment. However, plastic waste comes in different types such as thermoplastic or thermoset, which results in varied properties of polymer modified asphalt (PMA). In this work, four thermoplastic vulcanizates (TPVs) were prepared using different peroxide concentrations to produce four formulations of gel content (with varying extent of crosslinked part) in order to imitate the variation of plastic waste. All four TPVs were then mixed with asphalt at $5 \mathrm{wt} \%$ thus producing four formulations of PMA, which went through physical, rheological, and storage stability assessments. PMA with higher gel content possessed lower penetration and higher softening temperature, indicating physically harder appearance of PMA. Superpave parameters remained unchanged among different gel content PMA at temperatures of 64,70 , and $76{ }^{\circ} \mathrm{C}$. PMA with any level of gel content had lower Brookfield viscosity than PMA without gel content at a temperature of $135^{\circ} \mathrm{C}$. Higher gel content resulted in shorter storage stability measured with greater different softening temperatures between top and bottom layers of PMA after 5 days of $163^{\circ} \mathrm{C}$ storage. This study shows that asphalt with thermoset plastic waste is harder and easier to pave, thus making the non-recycling thermoset plastic waste more useful and friendly to the environment.
\end{abstract}

Keywords: polymer modified asphalt; thermoplastic vulcanizate; gel content; natural rubber; ethylene vinyl acetate copolymer; rheological properties; storage stability

\section{Introduction}

Plastics have been used in many applications since 1900s [1]. The accumulation of plastic waste has become a global concern, especially single-use plastic in the form of nonbiodegradable plastic [2-7]. Plastics are often released into the sea either intentionally or unintentionally, and accumulation of such waste is considered to be harmful or even toxic to marine lifeforms. Many solutions have been developed to solve this problem with the method of utilizing plastic waste being one such option, for example depolymerization [8], the recycling process $[9,10]$, or the blending of plastic waste with asphalt to prepare polymer modified asphalt [11-17]. The addition of plastics can improve the asphalt properties such as penetration, rutting resistance or Superpave parameter, and thermal stability.

Transportation is currently more convenient than ever. With cars being the main mode of transportation causing an increase in traffic load, the importance of good pavement is 
imperative. Polymer modified asphalt (PMA) has been introduced to improve the properties of pavement materials. The polymers can be classified into thermoplastic, thermoset, elastomer or rubber, and thermoplastic elastomer [18]. Thermoplastic such as polyethylene (PE) [19,20], polypropylene (PP) [21], polyethylene terephthalate (PET) [22] are used for the modification of asphalt, improving the rutting resistance and thermal cracking. However, due to the semi-crystallinity of thermoplastic, the elasticity of the material is still lacking at low temperature, thus limiting its applications. To improve the elasticity, an elastomer can be added to asphalt. Styrene butadiene copolymer (SBS) and styrene butadiene rubber are common elastomers used to improve asphalt's properties [23-26]. Moreover, to utilize the waste, crumb rubber is also used to improve physical properties of asphalt $[11,25,27,28]$. The crumb rubber, which is in the form of fully crosslinked rubber, is added into the asphalt as particles resulting in a lower degree of processability and the possibility of phase separation occurring during storage if kept for a long duration. Therefore, the combination of both thermoplastic and vulcanized elastomer should be used to improve the asphalt $[29,30]$.

Thermoplastic vulcanizate (TPV) is a material that has been widely used owing to its excellent elastic properties from the rubber particles and can be recycled like thermoplastic by melting [31,32]. Our previous work [33] has explored the suitable method for preparing thermoplastic vulcanizate from natural rubber and ethylene vinyl acetate copolymer to be used as a package of solidified asphalt. The "Split-DV" method was recommended to prepare the material pair that can be crosslinked using peroxide crosslinking agent. The aforementioned method also improved the compatibility of the involved materials by increasing degree of crosslink between plastic and rubber. The degree of crosslink of polymer can be described by gel content, which is the amount of insoluble sample remaining in hot solvent according to ASTM D2765 [34].

Moreover, there is a wide variety of plastic waste possessing different gel content, which affects the properties of PMA. To the best of our knowledge, there have been few studies focusing on the gel content of plastic waste before blending with asphalt. Rasool et al. [24] studied the effect of extrusion temperature on degraded tire blended with SBS and asphalt. High temperature resulted in more degraded rubber; thus, gel content of rubber decreased.

By imitating the plastic waste that contains various degrees of gel content, the present study focused on the effects of TPV gel content on properties of PMA. The TPV from natural rubber and ethylene vinyl acetate (EVA) copolymer with different gel content was mixed with asphalt to prepare PMA when the content of TPV was fixed at $5 \mathrm{wt} \%$. Appearances and physical properties, i.e., penetration value, softening temperature, and rheological properties of PMA, were evaluated. In addition, the Brookfield viscosity was measured.

\section{Materials and Methods}

\subsection{Materials}

Ethylene-vinyl acetate (EVA) copolymer, which was used as the thermoplastic, was purchased from TPI Polene Co., Ltd. (Bangkok, Thailand). Natural rubber (NR) sheet (air-dried sheet type) was purchased from Bothong cooperation (Chonburi, Thailand). Dicumyl peroxide (DCP), which was used as a crosslinking agent, was supplied by Arkema (Missouri, North Kansas City, MO, USA). Octadecyl-3-(3,5-di-tert butyl-4-hydroxyphenyl)propionate (Irganox1076) and tris(2,4-di-tert-butylphenyl)phosphate (Irgafos168), which were used as a thermal stabilizers, were purchased from Tokyo Chemical Industry Co., Ltd. (Tokyo, Japan). Asphalt binder (penetration grade, AC60/70) was obtained from Thai Lube Base Co., Ltd. (Bangkok, Thailand) Properties of the EVA, NR, DCP, and asphalt binder are shown in Table 1. Xylene, which was used as solvent to evaluate the gel content of thermoplastic vulcanizate, was used as received without further purification. 
Table 1. Properties of EVA, NR, DCP, and asphalt binder.

\begin{tabular}{|c|c|c|c|}
\hline Properties & Unit & Value & Standard \\
\hline \multicolumn{4}{|l|}{ Ethylene Vinyl Acetate (EVA) Copolymer } \\
\hline Vinyl acetate content & $w t \%$ & 18 & ASTM D5594 \\
\hline Density & $\mathrm{g} / \mathrm{cm}^{3}$ & 0.94 & ASTM D1505 \\
\hline Melt flow index $\left(2.16 \mathrm{~kg}, 190^{\circ} \mathrm{C}\right)$ & $\mathrm{g} / 10 \mathrm{~min}$ & 2.3 & ASTM D1238 \\
\hline Melting temperature & ${ }^{\circ} \mathrm{C}$ & 86 & ASTM D3418 \\
\hline \multicolumn{4}{|l|}{ Natural Rubber (NR) } \\
\hline Mooney viscosity $\left(100^{\circ} \mathrm{C}\right)$ & $\operatorname{ML}(1+4)$ & 59 & ASTM D1646 \\
\hline Density & $\mathrm{g} / \mathrm{cm}^{3}$ & 0.90 & ASTM D792 \\
\hline Glass transition temperature & ${ }^{\circ} \mathrm{C}$ & -67 & ASTM E1356 \\
\hline \multicolumn{4}{|l|}{ Dicumyl Peroxide (DCP) } \\
\hline Purity & $\%$ & 99.0 & ASTM E755 \\
\hline Active Oxygen & $\%$ & 5.9 & ASTM D2180 \\
\hline \multicolumn{4}{|l|}{ Half-life temperature } \\
\hline $10 \mathrm{~h}^{\mathrm{T}}$ & & 117 & \\
\hline $1 \mathrm{~h}$ & ${ }^{\circ} \mathrm{C}$ & 137 & \\
\hline $1 \mathrm{~min}$ & & 178 & \\
\hline \multicolumn{4}{|l|}{ Asphalt Binder (Penetration Grade, AC 60/70) } \\
\hline Penetration at $25^{\circ} \mathrm{C}(100 \mathrm{~g}, 5 \mathrm{~s})$ & $0.1 \mathrm{~mm}$ & 64 & ASTM D5 \\
\hline Ring-and-ball softening temperature & ${ }^{\circ} \mathrm{C}$ & 47 & ASTM D36 \\
\hline Brookfield viscosity at $135^{\circ} \mathrm{C}$ & $\mathrm{cP}$ & 297.5 & \\
\hline Shear rate $18.6 \mathrm{~s}^{-1}$, spindle 21 & Pas & 0.2975 & ASTM D4402 \\
\hline \multicolumn{4}{|l|}{$\left|\mathrm{G}^{*}\right| / \sin \delta(10 \mathrm{rad} / \mathrm{s}, 12 \%$ strain $)$ at } \\
\hline $58^{\circ} \mathrm{C}$ & & 3.06 & \\
\hline $64{ }^{\circ} \mathrm{C}$ & $\mathrm{kPa}$ & 1.29 & ASTM D7175 \\
\hline $70{ }^{\circ} \mathrm{C}$ & & 0.592 & \\
\hline Fail temperature (at $\left|\mathrm{G}^{*}\right| / \sin \delta=1 \mathrm{kPa}$ ) & ${ }^{\circ} \mathrm{C}$ & 66.0 & \\
\hline
\end{tabular}

\subsection{Sample Preparation}

The sample preparation contained two steps: preparation of thermoplastic vulcanizates and preparation of polymer modified asphalt. The overall experimental procedure is shown in Figure 1.

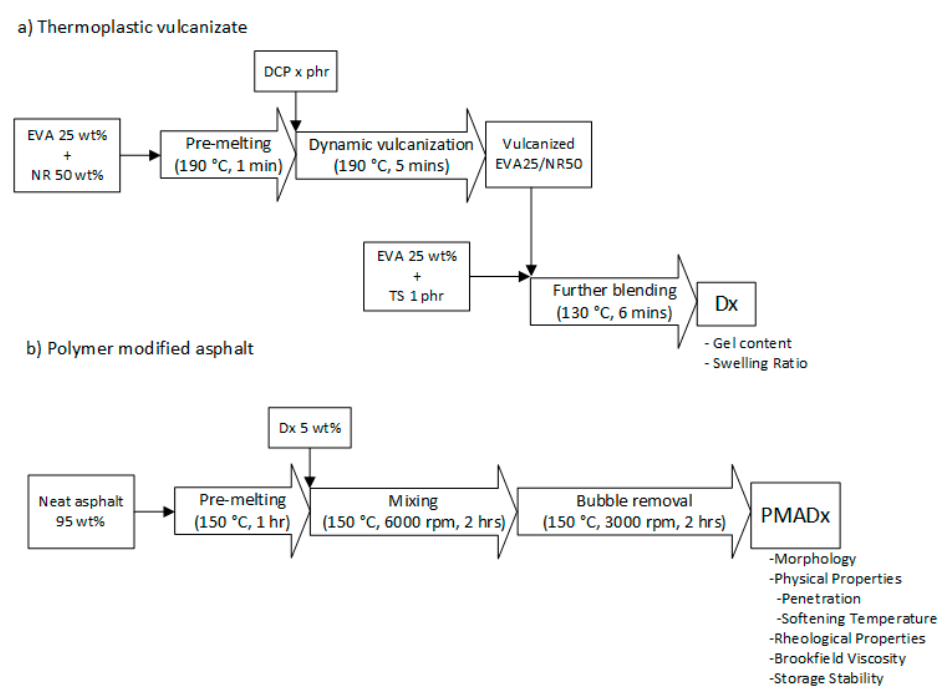

Figure 1. Experimental procedure of this research. (a) Preparation of thermoplastic vulcanizate; (b) preparation of polymer modified asphalt. " $\mathrm{x}$ " is DCP content. 


\subsubsection{Preparation of Thermoplastic Vulcanizates (TPVs)}

EVA pellets and NR sheets were dried in a vacuum oven at $60{ }^{\circ} \mathrm{C}$ for $4 \mathrm{~h}$ to remove moisture. The EVA/NR TPVs were prepared by melt-mixing in an internal mixer (Charoen Tut, Thailand) with chamber size of $60 \mathrm{~cm}^{3}$. According to our previous work [30], the suitable method used to prepare EVA/NR thermoplastic vulcanizate is the Split-DV method, which is shown in Figure 1a. Firstly, $25 \mathrm{wt} \%$ of EVA and $50 \mathrm{wt} \%$ of NR were pre-melted for $1 \mathrm{~min}$ and then dynamically vulcanized with the DCP for $5 \mathrm{~min}$ at $190{ }^{\circ} \mathrm{C}$ with a rotor speed of $60 \mathrm{rpm}$. After that, the product obtained from the previous step was melt-mixed with $25 \mathrm{wt} \%$ of EVA, and each thermal stabilizer (TS) of $0.5 \mathrm{phr}$ was added at $130{ }^{\circ} \mathrm{C}$ with a rotor speed of $60 \mathrm{rpm}$ for $6 \mathrm{~min}$. DCP was varied from 0 to $1.5 \mathrm{phr}$ to obtain the sample with different crosslinked degree. The samples were denoted as D0, D0.5, D1, and D1.5, and their appearance is shown in Figure 2. Gel content and swelling ratio of TPV was evaluated using the solvent extraction method according to ASTM D2765 [34]. The formulation, gel content, and swelling ratio of TPV are shown in Table 2.

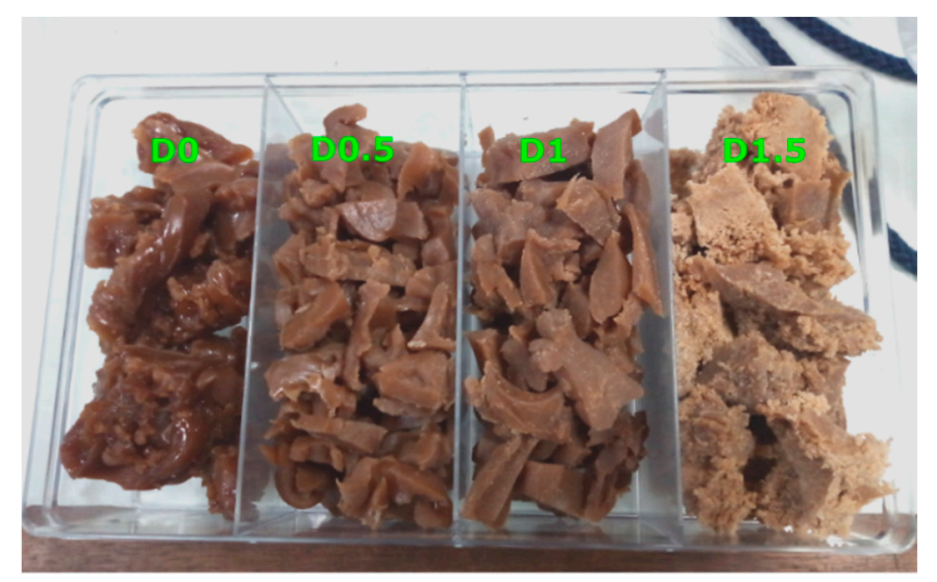

Figure 2. Appearance of EVA/NR thermoplastic vulcanizates at various DCP content.

Table 2. Formulations as well as gel content and swelling ratio of EVA/NR thermoplastic vulcanizates.

\begin{tabular}{|c|c|c|c|c|c|c|}
\hline \multirow[b]{2}{*}{ Sample Name } & \multicolumn{4}{|c|}{ Composition } & \multirow{2}{*}{$\begin{array}{c}\text { Gel Content } \\
(\%)\end{array}$} & \multirow{2}{*}{$\begin{array}{c}\text { Swelling Ratio } \\
(\%)\end{array}$} \\
\hline & $\begin{array}{c}\text { EVA } \\
(w t \%)\end{array}$ & $\begin{array}{c}\text { NR } \\
(w t \%)\end{array}$ & $\begin{array}{c}\text { DCP } \\
\left({ }^{*} \text { phr }\right)\end{array}$ & $\begin{array}{c}\text { TS } \\
\left({ }^{*} \text { phr }\right)\end{array}$ & & \\
\hline D0 & 50 & 50 & 0 & 1 & \multicolumn{2}{|c|}{ Totally soluble } \\
\hline D0.5 & 50 & 50 & 0.5 & 1 & $23.9 \pm 2.9$ & $1491.0 \pm 45.8$ \\
\hline D1 & 50 & 50 & 1 & 1 & $41.7 \pm 1.3$ & $1133.5 \pm 48.9$ \\
\hline D1.5 & 50 & 50 & 1.5 & 1 & $42.6 \pm 0.6$ & $1064.5 \pm 16.2$ \\
\hline
\end{tabular}

* phr $=$ parts per hundred resin.

\subsubsection{Preparation of Polymer Modified Asphalt (PMA)}

The asphalt was melted at $150{ }^{\circ} \mathrm{C}$ in a metal container. Each TPV sample obtained from a previous section was cut into small pieces $(\leq 2 \mathrm{~mm})$ and gradually mixed with asphalt at $5 \mathrm{wt} \%$ using a high-speed shear mixer (L5M model, Silverson, Massachusetts, USA) at $150{ }^{\circ} \mathrm{C}$ with a rotor speed of $6000 \mathrm{rpm}$ for $2 \mathrm{~h}$ and $3000 \mathrm{rpm}$ for $2 \mathrm{~h}$ in order to remove air bubbles from asphalt. The protocol was adapted from Fang et al. [35]. The suitable condition to mix EVA and crumb rubber (CR) with asphalt were a mixing temperature of $140{ }^{\circ} \mathrm{C}$, mixing time of $1.5 \mathrm{~h}$, and rotor speed of $3750 \mathrm{rpm}$. However, our samples were $2 \mathrm{~mm}$ pieces of TPV. At first, in the use of this protocol, the TPV was not well-dispersed in the asphalt. Therefore, the protocol had to be adjusted by increasing the temperature, the mixing time, and the rotor speed as described above.

After that, the appearance of neat asphalt and PMA was evaluated by pouring the neat asphalt or obtained samples into water at room temperature. After the sample was 
solidified, the solid asphalt was then stretched by hand, and the texture was observed. Each PMA is represented as PMADx where Dx is the TPV sample blended with asphalt at $5 \mathrm{wt} \%$. For example, PMAD0 is the asphalt modified with $5 \mathrm{wt} \%$ of D0 sample.

\subsection{Characterizations}

\subsubsection{Morphology}

The morphology of PMA related to dispersion of TPV in asphalt binder was observed with a fluorescence microscope (DM 2500P, Leica) with a magnification of $20 \times$. The sample was collected from the mixer and placed on a microscopic glass slide then covered with cover glass. The glass slide was placed in hot stage apparatus (T95-HS, Linkam, UK) and heated from room temperature to $150^{\circ} \mathrm{C}$ and then held at constant temperature of $150{ }^{\circ} \mathrm{C}$ until the molten asphalt became a thin film under the cover glass. Photographs were taken using a digital camera attached to the microscope.

\subsubsection{Physical Properties}

Physical properties such as penetration value of asphalt indicate the hardness of asphalt. The test was performed at $25{ }^{\circ} \mathrm{C}$ according to ASTM D5 [36]. Ring-and-ball softening temperature was measured according to ASTM D36 [37] with a heating rate of $5{ }^{\circ} \mathrm{C} / \mathrm{min}$.

\subsubsection{Performance Grading}

Performance grade of neat asphalt and PMA was evaluated according to ASTM D7175 [38] using a dynamic shear rheometer (Physica MCR 501, Anton Paar, Graz, Austria) using a constant strain of $12 \%$ and frequency of $10 \mathrm{rad} / \mathrm{s}$. The complex modulus $\left(\mathrm{G}^{*}\right)$ and phase angle $(\delta)$ were measured at specific strain and angular frequency. Afterwards, the Superpave parameter $\left(\left|G^{*}\right| / \sin \delta\right)$ was calculated. The initial temperature of testing was $58^{\circ} \mathrm{C}$ for neat asphalt and $64^{\circ} \mathrm{C}$ for the PMA. The temperature was increased at an increment of $6{ }^{\circ} \mathrm{C}$ for each test until the value of the Superpave parameter $\left(\left|\mathrm{G}^{*}\right| / \sin \delta\right)$ was lower than $1 \mathrm{kPa}$. Fail temperature of neat asphalt and PMA were calculated according to ASTM D7643 [39]. This Superpave parameter was introduced by the American Strategic Highway Research Program (SHRP). It is related to the stiffness of asphalt at a specific temperature. The Superpave parameter represents the property of asphalt in real traffic loading, which is usually in cycles.

\subsubsection{Rheological Properties}

Rheological properties of neat asphalt and PMA such as storage modulus $\left(G^{\prime}\right)$, loss modulus $\left(G^{\prime \prime}\right)$, phase angle $(\delta)$, and complex viscosity $\left(\eta^{*}\right)$ were measured using a dynamic shear rheometer (DSR) (Physica MCR 501, Anton Paar, Graz, Austria). The rheometer is a strain-controlled parallel-plate type. The test was performed in frequency-sweep mode with a plate diameter of $25 \mathrm{~mm}$, with a gap of $1 \mathrm{~mm}$ at constant temperature of $60{ }^{\circ} \mathrm{C}$ (which is the road average surface temperature in hot climate region [23,40-42]) with angular frequencies of $100-0.1 \mathrm{rad} / \mathrm{s}$ and a constant strain of $12 \%$, which is within the linear viscoelastic region of the asphalt (Figure S1).

\subsubsection{Brookfield Viscosity}

Brookfield viscosities of neat asphalt and PMA were measured using a Brookfield viscometer (DVIII, Brookfield) at a constant shear rate of $18.6 \mathrm{~s}^{-1}$ (rotor speed of $20 \mathrm{rpm}$ ) using spindle 21 geometry. The temperature was set at $135^{\circ} \mathrm{C}$. The viscosities were recorded every $1 \mathrm{~min}$ from 0 to $10 \mathrm{~min}$ and every $5 \mathrm{~min}$ until $60 \mathrm{~min}$. The equipment was set up according to ASTM D4402 [43].

\subsubsection{Storage Stability}

Storage stability or separation tendency of polymer from PMA was evaluated according to ASTM D7173 [44]. This test was performed only on the asphalt blended with 
polymer. The asphalt sample was poured into an aluminum tube with a diameter of $25.4 \mathrm{~mm}$ and height of $136.7 \mathrm{~mm}$. The tube was closed and stored in the oven at $163{ }^{\circ} \mathrm{C}$ for 5 days. The tube was cooled to $-10^{\circ} \mathrm{C}$ for $2 \mathrm{~h}$ and cut into three sections as shown in Figure S2. The difference of softening temperature of PMA collected from top and bottom sections of the tube was used to evaluate the storage stability of PMA.

\section{Results}

\subsection{Appearance, Morphology, and Physical Properties}

The appearance of neat asphalt and PMA at room temperature as well as their morphology at $150^{\circ} \mathrm{C}$ observed with the fluorescence microscope are shown in Figure 3. It was found that the neat asphalt (Figure 3a) exhibited a glossy texture, while the PMAD0 exhibited a matte texture (Figure 3c). Only neat asphalt and PMAD0 exhibited smooth texture, while the PMAD0.5, PMAD1, and PMAD1.5 showed rough texture as can be seen in Figure 3e,g,i, respectively. The TPV consisted of thermoplastic and crosslinked rubber particles, which could be observed by SEM (Figure S3) from our previous work [33]. Therefore, the dispersion of TPV in PMA was observed in the fluorescence micrographs at $20 \times$ magnification.

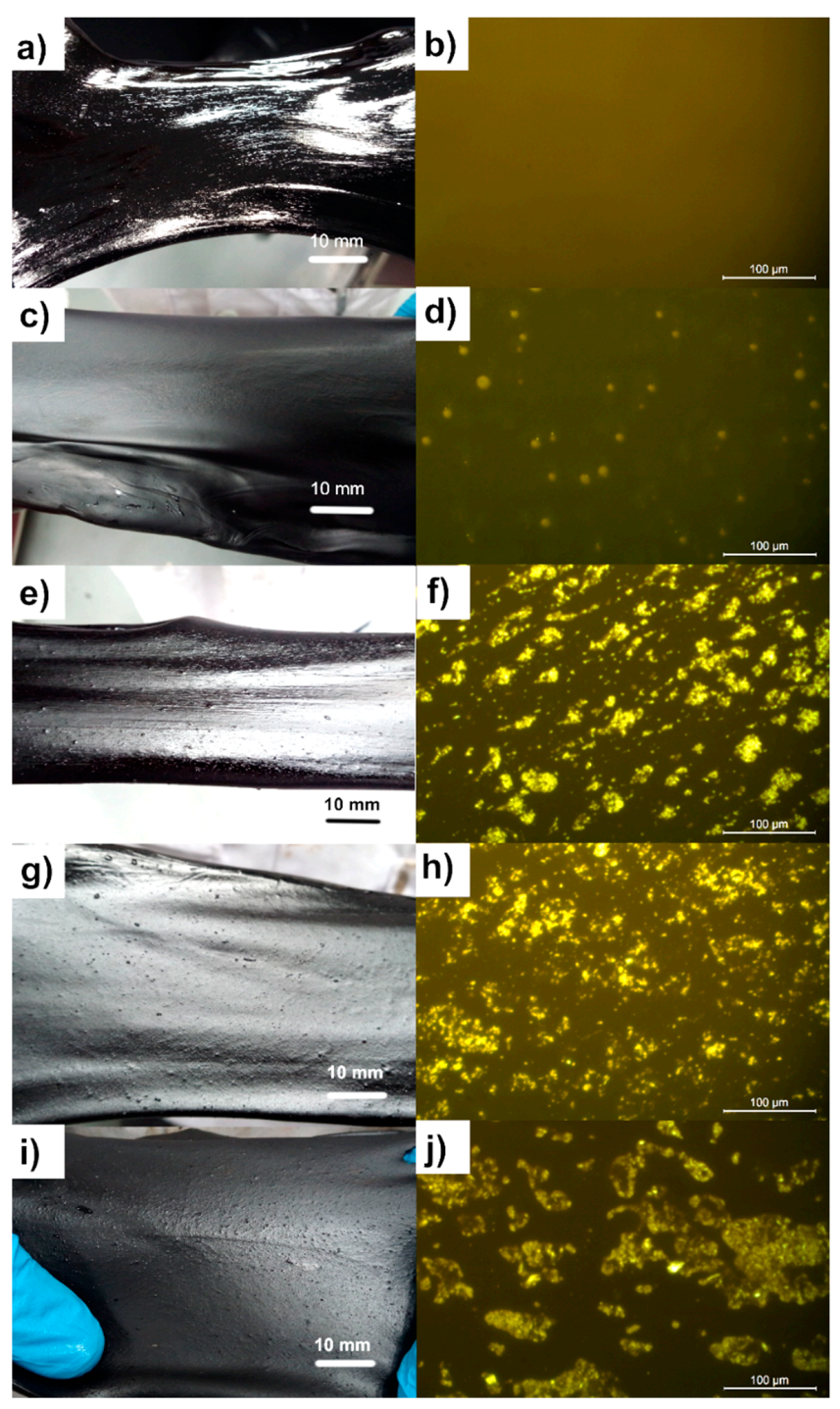

Figure 3. Optical images at room temperature and fluorescence micrographs at $150{ }^{\circ} \mathrm{C}$ of $(\mathbf{a}, \mathbf{b})$ neat asphalt, (c,d) PMAD0, (e,f) PMAD0.5, (g,h) PMAD1, and $(\mathbf{i}, \mathbf{j})$ PMAD1.5. The magnification of optical images and fluorescence micrographs were $1 \times$ and $20 \times$, respectively. 
The fluorescence micrograph of PMA exhibited heterogeneous morphology with different shape of dispersed phase (Figure $3 \mathrm{~d}, \mathrm{f}, \mathrm{h}, \mathrm{j}$, respectively). The dispersed phase of PMAD0 was in a spherical shape, while those in PMAD0.5, PMAD1, and PMAD1.5 were in an irregular shape. Morphology of asphalt blended with TPV was similar to that blended with the crumb rubber because the crumb rubber also consisted of the crosslinked rubber $[24,25,27]$. Crosslinked rubber is like a thermoset plastic that cannot be melted at high temperature. Therefore, it only dispersed in the asphalt as observed.

Physical properties such as penetration and ring-and-ball softening temperature (TRB) are shown in Table 3. It was found that PMA exhibited less penetration of needles and higher softening temperature than neat asphalt. With the increase of gel content of TPV, the penetration decreased, and the softening temperature slightly increased. Moreover, higher gel content led to a higher degree of crosslinking in TPV causing the samples to be more rigid and difficult to deform, thus improving the asphalt properties. The improvement in penetration and softening temperature of modified asphalt indicated that the samples here are suitable for use in hot climate regions. However, these values represent only the properties in a static situation and do not reflect real world usage because roads normally experience continuous loading and unloading of forces during traffic. Therefore, the rheological properties of asphalt were characterized and are discussed in the next section.

Table 3. Physical properties as well as Superpave parameter of neat asphalt and polymer modified asphalt.

\begin{tabular}{|c|c|c|c|c|c|c|c|}
\hline \multirow{2}{*}{ Sample Name } & \multirow{2}{*}{$\begin{array}{c}\text { Penetration } \\
(0.1 \mathrm{~mm}) \text { at } 25^{\circ} \mathrm{C}\end{array}$} & \multirow{2}{*}{$\begin{array}{l}T_{R B} \\
\left({ }^{\circ} \mathrm{C}\right)\end{array}$} & \multicolumn{4}{|c|}{$\left(\frac{\left|G^{*}\right|}{\sin \delta}\right)(\mathbf{k P a})$} & \multirow{2}{*}{ Fail Temperature $\left({ }^{\circ} \mathrm{C}\right)$} \\
\hline & & & $58^{\circ} \mathrm{C}$ & $64^{\circ} \mathrm{C}$ & $70^{\circ} \mathrm{C}$ & $76^{\circ} \mathrm{C}$ & \\
\hline Neat asphalt & $64 \pm 0$ & $47.0 \pm 0.3$ & 3.1 & 1.3 & 0.6 & - & 66.0 \\
\hline PMAD0 & $47 \pm 1$ & $53.9 \pm 0.3$ & - & 3.0 & 1.5 & 0.7 & 73.2 \\
\hline PMAD0.5 & $46 \pm 1$ & $54.5 \pm 0.1$ & - & 3.1 & 1.5 & 0.7 & 73.4 \\
\hline PMAD1 & $45 \pm 1$ & $55.8 \pm 0.8$ & - & 3.2 & 1.6 & 0.7 & 73.6 \\
\hline PMAD1.5 & $41 \pm 1$ & $54.8 \pm 0.4$ & - & 3.3 & 1.6 & 0.8 & 73.7 \\
\hline
\end{tabular}

\subsection{Performance Grading}

In this work, the neat asphalt and PMA were classified as Superpave performance grade classification. The Superpave parameters $\left(\left|G^{*}\right| / \sin \delta\right)$ at each temperature test and fail temperature are shown in Table 3. It was found that incorporation of TPV increased the fail temperature from 66.0 (neat asphalt) to $73.7^{\circ} \mathrm{C}$ (PMAD1.5). Moreover, $\left|\mathrm{G}^{*}\right| / \sin \delta$ of PMA was higher than that of neat asphalt by about 2.3 to 2.5 times. It can be said that the grade of modified asphalt was improved from the neat asphalt, and there was no significant difference between each PMA sample. Therefore, gel content of TPV has a small effect on the performance of asphalt compared to the content of TPV. However, the Superpave parameter was measured using constant frequency and amplitude. The real condition of traffic load must have both heavy and light load. Asphalt binder is a viscoelastic material. Therefore, the frequency sweep mode was used.

\subsection{Rheological Properties}

Rheological properties of neat asphalt and PMA in frequency sweep mode were evaluated to reflect the variation of force that the binder received during traffic transportation. Figure 4 shows rheological properties of neat asphalt and PMA and their values at frequencies of $0.1,1,10$, and $100 \mathrm{rad} / \mathrm{s}$, which are also summarized in Table 4 . It was found that storage modulus $\left(G^{\prime}\right)$, loss modulus $\left(G^{\prime \prime}\right)$, Superpave parameter $\left(\left|G^{*}\right| / \sin \delta\right)$, and complex viscosity $\left(\eta^{*}\right)$ of PMA were higher than those of neat asphalt, whereas phase angle ( $\delta$ ) of PMA was lower than that of neat asphalt in the test range, which indicated the improvement of asphalt by incorporation of TPV.

It was found that the $G^{\prime}$ of PMAD0.5 was higher than that of other PMA at low frequency range $(0.1-1 \mathrm{rad} / \mathrm{s})$, while it was positively correlated with gel content at high 
frequency range (10-100 rad/s). The G" of PMA increased with increase of gel content for all tested frequency values. Moreover, the $G^{\prime \prime}$ of all samples was higher than $G^{\prime}$, and there was no crossover point between $G^{\prime}$ and $G^{\prime \prime}$, which means that the behavior of PMA was viscous-dominant in the tested conditions. It can be observed that the loss modulus (Figure $4 \mathrm{~b}$ ), complex modulus (Figure S3), and $\left|\mathrm{G}^{*}\right| / \sin \delta$ were similar. The phase angle (Figure 4c) of PMA was lower than that of neat asphalt. It was found that the PMAD0.5 showed the lowest phase angle at low angular frequency, while there was no significant difference at high angular frequency.

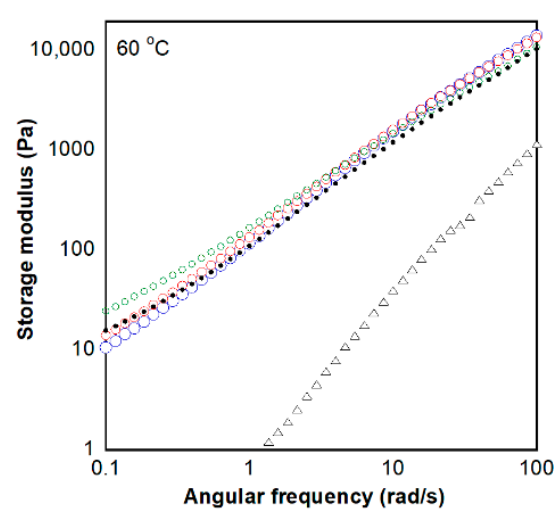

a)

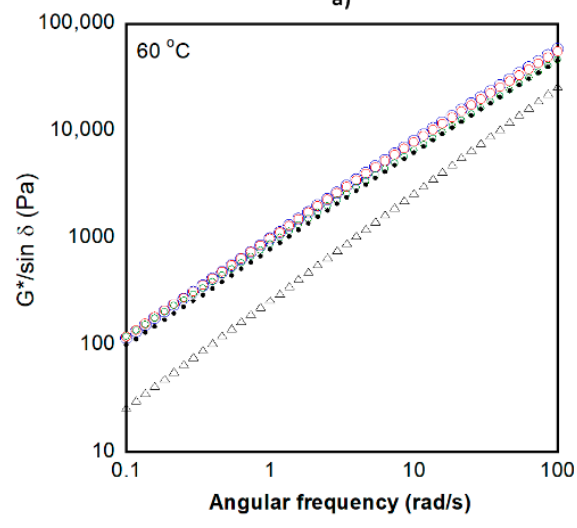

c)

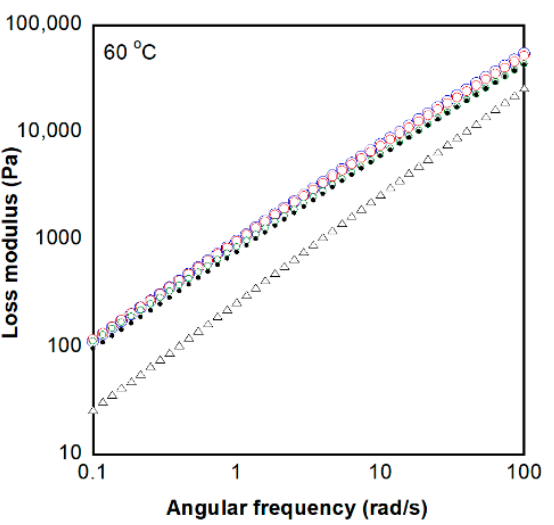

b)

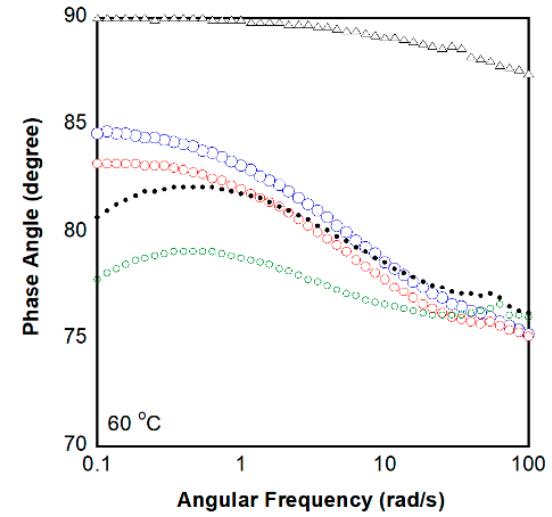

d)

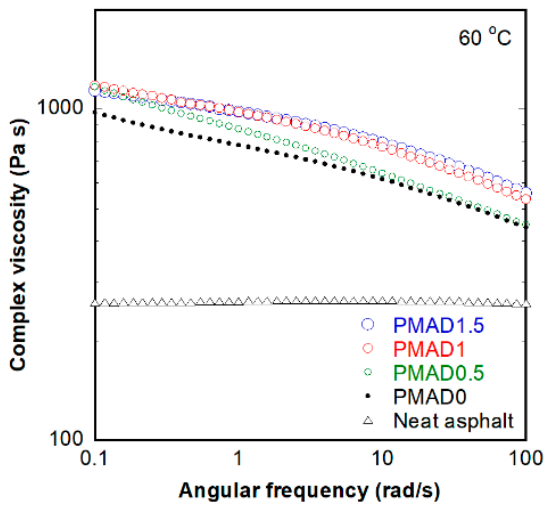

e)

Figure 4. Rheological properties of neat asphalt and PMA at $60^{\circ} \mathrm{C}$ in frequency sweep mode: (a) storage modulus, (b) loss modulus, (c) Superpave parameter, (d) phase angle, and (e) complex viscosity. 
Table 4. Rheological properties of neat asphalt and PMA at $60^{\circ} \mathrm{C}$.

\begin{tabular}{|c|c|c|c|c|c|}
\hline \multirow{2}{*}{ Parameters } & \multirow{2}{*}{ Sample } & \multicolumn{4}{|c|}{ Angular Frequency (rad/s) } \\
\hline & & $\omega=0.1$ & $\omega=1$ & $\omega=10$ & $\omega=100$ \\
\hline \multirow{5}{*}{ Storage modulus (Pa) } & Neat asphalt & 0.020 & 0.599 & 40 & 1180 \\
\hline & PMAD0 & 15.8 & 111 & 1220 & 10,500 \\
\hline & PMAD0.5 & 24.7 & 169 & 1490 & 10,900 \\
\hline & PMAD1 & 14.1 & 136 & 1630 & 13,700 \\
\hline & PMAD1.5 & 10.7 & 118 & 1560 & 14,300 \\
\hline \multirow{5}{*}{ Loss modulus (Pa) } & Neat asphalt & 26 & 263 & 2650 & 26,000 \\
\hline & PMAD0 & 96.6 & 772 & 6030 & 42,700 \\
\hline & PMAD0.5 & 114 & 856 & 6240 & 43,500 \\
\hline & PMAD1 & 118 & 972 & 7520 & 51,700 \\
\hline & PMAD1.5 & 114 & 976 & 7770 & 54,100 \\
\hline \multirow{5}{*}{$\mathrm{G}^{*} / \sin \delta(\mathrm{Pa})$} & Neat asphalt & 26.1 & 263 & 2650 & 26,000 \\
\hline & PMAD0 & 99.2 & 788 & 6280 & 45,300 \\
\hline & PMAD0.5 & 120 & 890 & 6590 & 46,200 \\
\hline & PMAD1 & 119 & 991 & 7880 & 55,300 \\
\hline & PMAD1.5 & 115 & 991 & 8080 & 57,900 \\
\hline \multirow{5}{*}{$\begin{array}{l}\text { Phase angle } \\
\text { (degree) }\end{array}$} & Neat asphalt & 90.0 & 89.9 & 89.1 & 87.4 \\
\hline & PMAD0 & 80.7 & 81.8 & 78.6 & 76.2 \\
\hline & PMAD0.5 & 77.8 & 78.8 & 76.6 & 76.0 \\
\hline & PMAD1 & 83.2 & 82.0 & 77.8 & 75.1 \\
\hline & PMAD1.5 & 84.6 & 83.1 & 78.6 & 75.2 \\
\hline \multirow{5}{*}{ Complex viscosity $(\mathrm{Pa} \cdot \mathrm{s})$} & Neat asphalt & 261 & 263 & 265 & 260 \\
\hline & PMAD0 & 979 & 780 & 615 & 440 \\
\hline & PMAD0.5 & 1170 & 873 & 641 & 448 \\
\hline & PMAD1 & 1180 & 981 & 770 & 535 \\
\hline & PMAD1.5 & 1140 & 984 & 792 & 559 \\
\hline
\end{tabular}

Complex viscosities of neat asphalt and PMA are shown in Figure 4d. The complex viscosity of neat asphalt was independent of angular frequency, indicating that the neat asphalt behaves as a Newtonian fluid in the testing range. However, the complex viscosity of PMA, which contained TPV, showed a frequency dependent behavior; the complex viscosity decreased with an increase in angular frequency. This behavior is non-Newtonian in nature with the type being pseudoplastic or shear thinning. The complex viscosity of PMA increased with increasing gel content of TPV at both low and high angular frequencies.

\subsection{Brookfield Viscosity}

Brookfield viscosity was measured using the Brookfield rotational viscometer at $135^{\circ} \mathrm{C}$. The viscosity of neat asphalt and PMA was recorded for $60 \mathrm{~min}$ as shown in Figure 5. The initial Brookfield viscosity value from the instrument was recorded at $2.500 \mathrm{~Pa} \cdot \mathrm{s}(2500 \mathrm{cP})$, which is the maximum value that can be measured by the instrument. The viscosities of neat asphalt and PMA decreased with time and remained stable after $10 \mathrm{~min}$ as shown in Figure 5. It was found that the Brookfield viscosity of PMA was higher than that of the neat asphalt due to the TPV restricting the mobility of asphalt. The PMAD1.5, which has the highest gel content, showed the lowest viscosity, while the PMAD0, which has no gel content, exhibited the highest viscosity among all the PMA samples. 


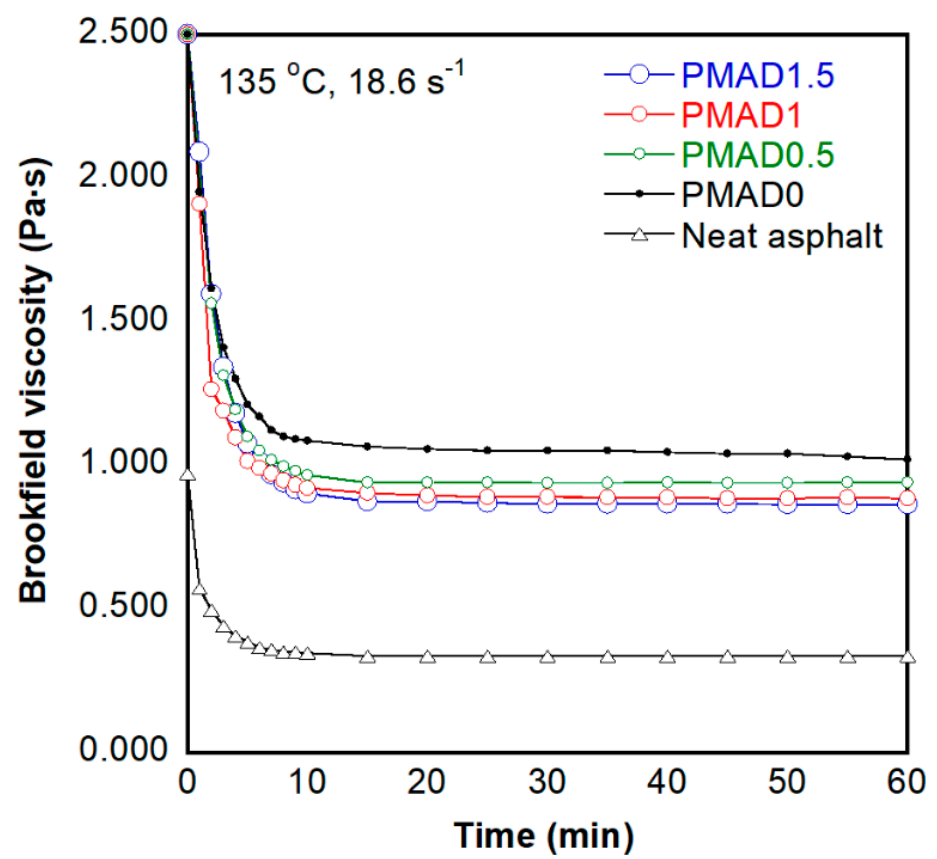

Figure 5. Brookfield viscosity of neat asphalt and PMA at $135^{\circ} \mathrm{C}$.

\subsection{Storage Stability}

The storage stability of polymer modified asphalt was evaluated by the difference of softening temperature of asphalt collected from the top and bottom sections of the tested aluminum tube. The higher difference in temperature refers to more polymer separation from the asphalt. The density of polymer is lower than that of asphalt. Therefore, the polymer tends to float over the asphalt surface during separation. The values of softening temperature of PMA before and after storage at $163{ }^{\circ} \mathrm{C}$ for 5 days are shown in Table 5.

Table 5. Storage stability of PMA contained different TPV after storage at $163^{\circ} \mathrm{C}$ for 5 days.

\begin{tabular}{ccccc}
\hline \multirow{2}{*}{ Formula } & \multicolumn{4}{c}{ Softening Temperature $\left({ }^{\circ} \mathbf{C}\right)$} \\
\cline { 2 - 5 } & Original & \multicolumn{2}{c}{ After Storage at 163 ${ }^{\circ} \mathbf{C}$ for 5 Days } \\
\cline { 2 - 5 } & & Top & Bottom & Difference \\
\hline Neat asphalt & 47.0 & - & - & - \\
PMAD0 & 53.9 & 55.4 & 53.6 & 1.8 \\
PMAD0.5 & 54.5 & 57.2 & 55.0 & 2.2 \\
PMAD1 & 55.8 & 58.5 & 56.1 & 2.4 \\
PMAD1.5 & 54.8 & 60.8 & 52.1 & 8.7 \\
\hline
\end{tabular}

It was found that PMAD0 showed the lowest difference in softening temperature, while the PMAD1.5 showed the highest value.

\section{Discussion}

The content of TPV in PMA of the present study was fixed at $5 \mathrm{wt} \%$ (EVA $2.5 \mathrm{wt} \%$ and NR $2.5 \mathrm{wt} \%$ ) because the asphalt is in continuous phase at this content, as can be observed from Figure 3. It would be convenient to observe the different shape of dispersed phase from TPV with different gel content. According to Sengoz et al. [45]'s work, the polymer entered continuous phase when content of polymer was more than $5 \mathrm{wt} \%$.

Appearances of neat asphalt and PMAD0, which is the asphalt blended with D0, exhibited smooth surface while other PMAs exhibited rough surface. The physical properties of PMA such as penetration and softening temperature were affected by gel content of TPV. High gel content of TPV in PMA resulted in harder PMA as seen in the lower penetra- 
tion value (higher degree of hardness) and higher softening temperature. This is consistent with the findings of Yan et al. [11] that crumb rubber (CR) content affected penetration and softening temperature more than that of EVA content. Changes of physical properties could probably be due to a different degree of crosslinking. According to Qian and Fan [25], addition of styrene-butadiene-styrene block copolymer (SBS) in rubberized asphalt containing $20 \mathrm{wt} \%$ CR can decrease the penetration value from 60 (0 wt $\%$ SBS) to 40 (3 wt $\%$ SBS). For EVA and CR modified asphalt, a penetration value of 40 can be observed from the asphalt modified with EVA $4 \mathrm{wt} \%$ and CR $10 \mathrm{wt} \%$ [11]. It seemed that TPV could achieve similar penetration from addition of only $5 \mathrm{wt} \%$ into asphalt.

The incorporation of TPV also increased the Superpave parameter $\left(\left|\mathrm{G}^{*}\right| / \sin \delta\right)$ of PMA compared to the neat asphalt. However, the gel content of TPV had a small improvement effect on PMA in test conditions in which the Superpave parameter was measured using constant frequency and amplitude. The real condition of traffic load must have both heavy and light load. Asphalt binder is a viscoelastic material. Therefore, the rheological properties of neat asphalt and PMA in frequency sweep mode were analyzed.

Rheological properties of PMA at $60^{\circ} \mathrm{C}$ such as storage modulus, loss modulus, Superpave parameter, and complex viscosity at high frequency range increased with the increase of gel content of TPV blended with asphalt, indicating that the material was more resistant to deformation due to crosslink in TPV. In this condition, the TPVs acted as particles to restrict the flow of PMA. For the low frequency range, the PMAD0.5 has the highest storage modulus and the lowest phase angle. According to the highest value of swelling ratio of D0.5 compared with other TPV, the asphalt might be absorbed in the 3D network of D0.5 more than D1 and D1.5. Therefore, the more swollen TPV showed more elastic behavior of polymer modified asphalt than the less swollen TPV. This result corresponded with the results from Yu et al. [46] that gel type bitumen possessed higher complex modulus and lower phase angle than the sol type bitumen. Although the frequency sweep test could provide preliminary information about PMA, to deeply investigate the fatigue resistance and elasticity performance of PMA, the linear amplitude sweep test (LAS) and multiple stress creep recovery (MSCR) should be further characterized.

As observed from Figure 4 (complex viscosity) and Figure 5 (Brookfield viscosity), the trend of viscosities of each sample measured by dynamic shear rheometer (DSR) was different from those measured by the Brookfield viscometer, which could be due to the different state of the polymer contained in the asphalt. The Brookfield viscosity was measured at a temperature higher than $135^{\circ} \mathrm{C}$, while the complex viscosity from DSR was measured at $60{ }^{\circ} \mathrm{C}$. According to the melting temperature of EVA of $86^{\circ} \mathrm{C}$, the state of EVA in asphalt during the DSR test is solid, while that of EVA during the Brookfield test is molten. In the molten state, the polymer chains were dispersed in asphalt as a random coil. The TPVs with no crosslinked part (D0) were in the form of a long-chain polymer, which could entangle together, whereas the TPV with dynamically vulcanized fine rubber (D0.5, D1, D1.5) might have lower content of long-chain polymer compared with the D0 sample.

Figure 6a shows a schematic drawing of TPV dispersed in asphalt in the molten state, which had different gel content. The difference between long-chain and short-chain polymers was the degree of entanglement, which affected the flowability of the asphalt, with the short chain polymer resulting in low viscosity due to the low to non-existent degree of entanglement. The dispersion of TPV during the Brookfield viscosity measurement is illustrated in Figure 6b. Figure $6 \mathrm{c}$ shows the changes of microstructure of PMA when the shear force was applied. The long polymer chain could be stretched, and the entangled points restricted the movement, which needed shear stress to disentangle the polymer chains. According to previous studies $[47,48]$, the media with high aspect ratio fiber was more viscous than that with low aspect ratio fiber as well as spherical particles. This is a hypothesis from an indirect result and some studies. The microstructure of PMA containing different structure of polymer at high temperature should be further investigated to clarify the explanation. 
a) With different TPV samples

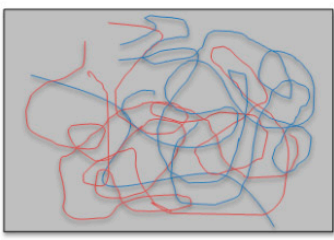

PMAD0

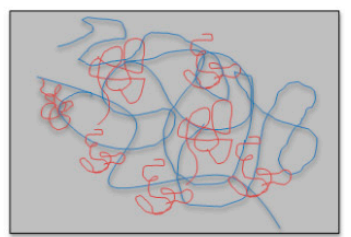

PMAD1

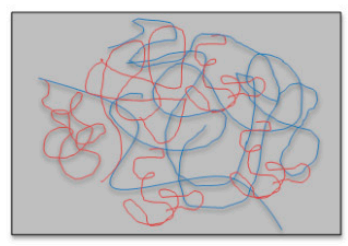

PMAD0.5

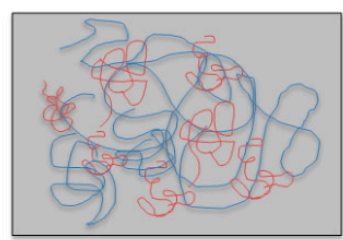

PMAD1.5

\section{b) Brookfield viscometer measurement}

NR long chain

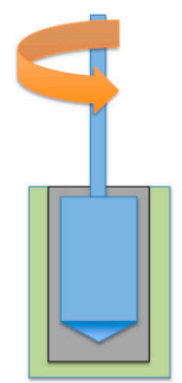

Neat asphalt

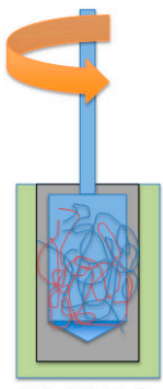

PMAD0

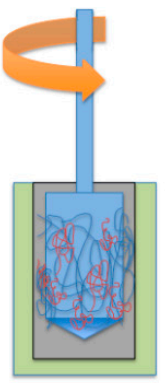

PMAD1.5

\section{EVA long chain}

EVA gel

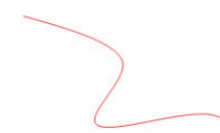

\section{c) When the shear force was applied}

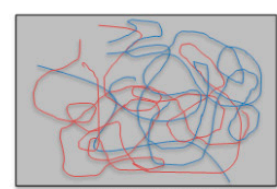

PMAD0

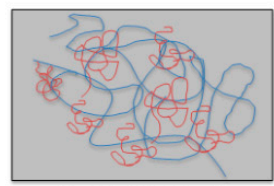

PMAD1.5

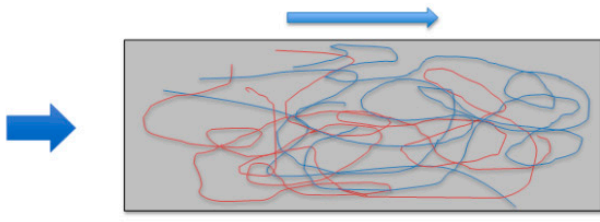

$\longrightarrow$
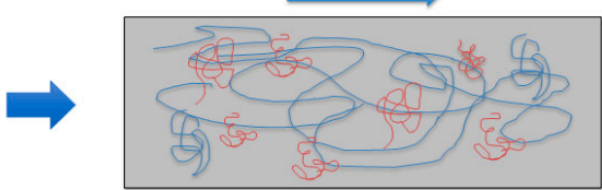

NR gel

Asphalt

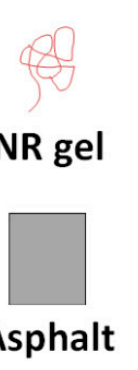


the PMAD1.5 did not pass the specification of both PMA and NRMA and should not be used to prepare the PMA. It also did not pass the criteria of asphalt binder according to the specifications of the Department of Highways (Thailand).

\section{Conclusions}

Four thermoplastic vulcanizates of ethylene vinyl acetate copolymer and natural rubber with different gel content were assessed for physical and rheological properties and storage stability of polymer modified asphalt (PMA). Four formulations of PMA denoted as PMAD0, PMAD0.5, PMAD1, and PMAD1.5 were prepared with peroxide of 0, 0.5, 1, and 1.5 phr, respectively.

PMA with greater cross-linked TPV had a higher degree of hardness (penetration values of neat asphalt: 64, PMAD0: 47, D0.5: 46, D1: 45, and D1.5: 41) and higher softening temperatures (neat asphalt: $47.0^{\circ} \mathrm{C}$, PMAD0: $53.9^{\circ} \mathrm{C}$, D0.5: $54.5^{\circ} \mathrm{C}$, D1: $55.8^{\circ} \mathrm{C}$, and D1.5: $\left.54.8^{\circ} \mathrm{C}\right)$. The Superpave parameter $\left(\left|\mathrm{G}^{*}\right| / \sin \delta\right)$ of PMA with any of TPV was higher than that of neat asphalt (neat asphalt: $1.3 \mathrm{kPa}$, PMAD0: $3.0 \mathrm{kPa}, \mathrm{D} 0.5: 3.1 \mathrm{kPa}, \mathrm{D} 1: 3.2 \mathrm{kPa}$, and D1.5: $3.3 \mathrm{kPa}$ ). This reflects the resistance to permanent deformation of PMA with TPV. Complex viscosities of PMA at a frequency of $10 \mathrm{rad} / \mathrm{s}$ were positively correlated with level of gel content (neat asphalt: $265 \mathrm{~Pa} \cdot \mathrm{s}, \mathrm{PMAD0}$ : $615 \mathrm{~Pa} \cdot \mathrm{s}, \mathrm{D} 0.5$ : $641 \mathrm{~Pa} \cdot \mathrm{s}, \mathrm{D} 1: 770 \mathrm{~Pa} \cdot \mathrm{s}$, and D1.5: $792 \mathrm{~Pa} \cdot \mathrm{s})$, while Brookfield viscosity appeared differently. As gel content was increased, Brookfield viscosity decreased (neat asphalt: $0.300 \mathrm{~Pa} \cdot \mathrm{s}, \mathrm{PMAD0}$ : $1.027 \mathrm{~Pa} \cdot \mathrm{s}$, D0.5: $0.859 \mathrm{~Pa} \cdot \mathrm{s}, \mathrm{D} 1: 0.805 \mathrm{~Pa} \cdot \mathrm{s}$, and D1.5: $0.802 \mathrm{~Pa} \cdot \mathrm{s})$. As Brookfield viscosity was assessed at $135^{\circ} \mathrm{C}$, which is higher than the melting temperature of EVA at $86^{\circ} \mathrm{C}$, while complex viscosity was assessed at $60^{\circ} \mathrm{C}$, it is highly probable that melted EVA contributes to lower viscosity at high temperature. Adding more thermoset plastic to PMA could result in lower viscosity. Although Brookfield viscosity of neat asphalt is the lowest, neat asphalt has a lower Superpave parameter and degree of hardness. Adding thermoset plastic seems to improve physical and rheological properties of asphalt. The only disadvantage is worse storage stability of PMA, which challenges further investigations. We believe that adding thermoset plastic to form PMA has benefits of both improving asphalt and keeping the environment safer.

Supplementary Materials: The following are available online at www.mdpi.com/xxx/s1, Figure S1: Rheological properties as a function of strain of neat asphalt at $60{ }^{\circ} \mathrm{C}$, Figure S2: Appearance of aluminum tube and its three section: Top, Middle, and Bottom. The softening temperature of PMA from top and bottom section was evaluated, Figure S3: Fractured surfaces of EVA/NR TPVs with magnification of 2000 and 5000, Table S1: Specification of asphalt cement, natural rubber modified asphalt and polymer modified asphalt (based on SBS) from department of highways (Thailand).

Author Contributions: Conceptualization, A.S.; methodology, N.K.; validation, N.K.; resources, B.S.; writing - original draft preparation, N.K.; writing—review and editing, B.S.; supervision, A.S.; All authors have read and agreed to the published version of the manuscript.

Funding: This research was funded by the Research and Researchers for Industries, Thailand Research Fund Scholarship (RRi-TRF), grant number PHD58I0027.

Institutional Review Board Statement: Not applicable.

Informed Consent Statement: Not applicable.

Data Availability Statement: The data presented in this study are available on request from the corresponding author.

Acknowledgments: The authors also thank the Fuels \& Lubes Laboratory, PTT Innovation Institute for supporting of materials and instruments. Moreover, the author would like to extend our gratitude to Chaiyos Kunanusont for his support in improvement of this manuscript.

Conflicts of Interest: The authors declare no conflict of interest. The funders had no role in the design of the study; in the collection, analyses, or interpretation of data; in the writing of the manuscript; or in the decision to publish the results. 


\section{References}

1. Science History Institute. History and Future of Plastics. Available online: https:/ /www.sciencehistory.org/the-history-andfuture-of-plastics\#: \{\}:text=In\%201907\%20Leo\%20Baekeland\%20invented, the\%20rapidly\%20electrifying\%20United\%20States (accessed on 5 April 2021).

2. Horodytska, O.; Valdes, F.J.; Fullana, A. Plastic flexible films waste management-A state of art review. Waste Manag. 2018, 77, 413-425. [CrossRef]

3. Ragaert, K.; Delva, L.; Van Geem, K. Mechanical and chemical recycling of solid plastic waste. Waste Manag. 2017, 69, 24-58. [CrossRef] [PubMed]

4. Singh, N.; Hui, D.; Singh, R.; Ahuja, I.P.S.; Feo, L.; Fraternali, F. Recycling of plastic solid waste: A state of art review and future applications. Compos. Part B Eng. 2017, 115, 409-422. [CrossRef]

5. United Nations Environment Programme. From Birth to Ban: A History of the Plastic Shopping Bag. Available online: https:/ / www.unenvironment.org/news-and-stories/story/birth-ban-history-plastic-shopping-bag\#: \{\{:text=1965\%20\%E2\%8 0\%93\%20The\%20one\%2Dpiece\%20polyethylene,cloth\%20and\%20plastic\%20in\%20Europe (accessed on 27 March 2021).

6. Jambeck, J.R.; Geyer, R.; Wilcox, C.; Siegler, T.R.; Perryman, M.; Andrady, A.; Narayan, R.; Law, K.L. Plastic waste inputs from land into the ocean. Science 2015, 347, 768. [CrossRef] [PubMed]

7. Gerritse, J.; Leslie, H.A.; de Tender, C.A.; Devriese, L.I.; Vethaak, A.D. Fragmentation of plastic objects in a laboratory seawater microcosm. Sci. Rep. 2020, 10, 10945. [CrossRef] [PubMed]

8. Miao, Y.; von Jouanne, A.; Yokochi, A. Current Technologies in Depolymerization Process and the Road Ahead. Polymers 2021, 13, 449. [CrossRef] [PubMed]

9. Wichai-utcha, N.; Chavalparit, O. 3Rs Policy and plastic waste management in Thailand. J. Mater. Cycles Waste Manag. 2018, 21, 10-22. [CrossRef]

10. Chotthong, B. Public-Private-People Partnerships on Plastic Waste Management in Thailand. Available online: http: / / eascongress2018.pemsea.org/wp-content/uploads/2018/12/S2.3-10-Public-Private-People-Partnerships-on-Plastic-WasteManagement-in-Thailand_BChotthong.pdf (accessed on 20 February 2020).

11. Yan, K.; Chen, J.; You, L.; Tian, S. Characteristics of compound asphalt modified by waste tire rubber (WTR) and ethylene vinyl acetate (EVA): Conventional, rheological, and microstructural properties. J. Clean. Prod. 2020, 258, 120723. [CrossRef]

12. Dalhat, M.A.; Al-Abdul Wahhab, H.I. Performance of recycled plastic waste modified asphalt binder in Saudi Arabia. Int. J. Pavement Eng. 2017, 18, 349-357. [CrossRef]

13. Dow. Recycled Polymer Modified Asphalt. Available online: https://www.dow.com/en-us/market/mkt-building-construction/ sub-build-construction-chem/app-build-constchem-asphalt-modification/recycled-polymer-modified-asphalt.html (accessed on 1 August 2020).

14. Lo Presti, D. Recycled Tyre Rubber Modified Bitumens for road asphalt mixtures: A literature review. Constr. Build. Mater. 2013, 49, 863-881. [CrossRef]

15. Almeida e Silva, J.D.A.; Rodrigues, J.K.G.; de Carvalho, M.W.; Lucena, L.C.F.L.; Cavalcante, E.H. Rheological evaluation of binder modified with micronized polyethylene terephthalate (PET). Rev. Mater. 2018, 23. [CrossRef]

16. Padhan, R.K.; Mohanta, C.; Sreeram, A.; Gupta, A. Rheological evaluation of bitumen modified using antistripping additives synthesised from waste polyethylene terephthalate (PET). Int. J. Pavement Eng. 2018, 21, 1083-1091. [CrossRef]

17. Dalhat, M.A.; Adesina, A.Y. Utilization of micronized recycled polyethylene waste to improve the hydrophobicity of asphalt surfaces. Constr. Build. Mater. 2020, 240, 117966. [CrossRef]

18. Porto, M.; Caputo, P.; Loise, V.; Eskandarsefat, S.; Teltayev, B.; Oliviero Rossi, C. Bitumen and Bitumen Modification: A Review on Latest Advances. Appl. Sci. 2019, 9, 742. [CrossRef]

19. Liang, M.; Xin, X.; Fan, W.; Wang, H.; Jiang, H.; Zhang, J.; Yao, Z. Phase behavior and hot storage characteristics of asphalt modified with various polyethylene: Experimental and numerical characterizations. Constr. Build. Mater. 2019, 203, 608-620. [CrossRef]

20. Okhotnikova, E.S.; Frolov, I.N.; Ganeeva, Y.M.; Firsin, A.A.; Yusupova, T.N. Rheological behavior of recycled polyethylene modified bitumens. Pet. Sci. Technol. 2019, 37, 1136-1142. [CrossRef]

21. Vamegh, M.; Ameri, M.; Chavoshian Naeni, S.F. Experimental investigation of effect of PP/SBR polymer blends on the moisture resistance and rutting performance of asphalt mixtures. Constr. Build. Mater. 2020, 253, 119197. [CrossRef]

22. Ahmadinia, E.; Zargar, M.; Karim, M.R.; Abdelaziz, M.; Ahmadinia, E. Performance evaluation of utilization of waste Polyethylene Terephthalate (PET) in stone mastic asphalt. Constr. Build. Mater. 2012, 36, 984-989. [CrossRef]

23. Qian, C.; Fan, W.; Liang, M.; He, Y.; Ren, S.; Lv, X.; Nan, G.; Luo, H. Rheological properties, storage stability and morphology of CR/SBS composite modified asphalt by high-cured method. Constr. Build. Mater. 2018, 193, 312-322. [CrossRef]

24. Rasool, R.t.; Song, P.; Wang, S. Thermal analysis on the interactions among asphalt modified with SBS and different degraded tire rubber. Constr. Build. Mater. 2018, 182, 134-143. [CrossRef]

25. Qian, C.; Fan, W. Evaluation and characterization of properties of crumb rubber/SBS modified asphalt. Mater. Chem. Phys. 2020, 253, 123319. [CrossRef]

26. Islam, S.S.; Singh, S.K.; Ransinchung, G.D.; Ravindranath, S.S. Effect of property deterioration in SBS modified binders during storage on the performance of asphalt mix. Constr. Build. Mater. 2021, 272, 121644. [CrossRef] 
27. López-Moro, F.J; Moro, M.C.; Hernández-Olivares, F.; Witoszek-Schultz, B.; Alonso-Fernández, M. Microscopic analysis of the interaction between crumb rubber and bitumen in asphalt mixtures using the dry process. Constr. Build. Mater. 2013, 48, 691-699. [CrossRef]

28. Xiao, F.; Yao, S.; Wang, J.; Wei, J.; Amirkhanian, S. Physical and chemical properties of plasma treated crumb rubbers and high temperature characteristics of their rubberised asphalt binders. Road Mater. Pavement Des. 2020, 21, 587-606. [CrossRef]

29. Favakeh, M.; Bazgir, S.; Karbasi, M. Dynamically vulcanized thermoplastic elastomer nanocomposites based on linear low-density polyethylene/styrene-butadiene rubber/nanoclay/bitumen: Morphology and rheological behavior. Iran. Polym. J. 2020, 29, 209-217. [CrossRef]

30. Wang, S.; Wang, Q.; Wu, X.; Zhang, Y. Asphalt modified by thermoplastic elastomer based on recycled rubber. Constr. Build. Mater. 2015, 93, 678-684. [CrossRef]

31. Naskar, K.; Babu, R.R. Thermoplastic Elastomers (TPEs) and Thermoplastic Vulcanizates (TPVs). In Encyclopedia of Polymeric Nanomaterials; Kobayashi, S., Müllen, K., Eds.; Springer: Berlin/Heidelberg, Germany, 2014. [CrossRef]

32. Ning, N.; Li, S.; Wu, H.; Tian, H.; Yao, P.; Hu, G.-H.; Tian, M.; Zhang, L. Preparation, microstructure, and microstructure-properties relationship of thermoplastic vulcanizates (TPVs): A review. Prog. Polym. Sci. 2018, 79, 61-97. [CrossRef]

33. Kunanusont, N.; Samthong, C.; Bowen, F.; Yamaguchi, M.; Somwangthanaroj, A. Effect of Mixing Method on Properties of Ethylene Vinyl Acetate Copolymer/Natural Rubber Thermoplastic Vulcanizates. Polymers 2020, 12, 1739. [CrossRef] [PubMed]

34. ASTM International. Standard Test Methods for Determination of Gel Content and Swell Ratio of Crosslinked Ethylene Plastics; ASTM International: West Conshohocken, PA, USA, 2001; Volume ASTM D2765-01.

35. Fang, C.; Qiao, X.; Yu, R.; Yu, X.; Liu, J.; Yu, J.; Xia, R. Influence of modification process parameters on the properties of crumb rubber/EVA modified asphalt. J. Appl. Polym. Sci. 2016, 133. [CrossRef]

36. ASTM International. Standard Test Method for Penetration of Bituminous Materials; ASTM International: West Conshohocken, PA, USA, 2020; Volume ASTM D5/D5M-20.

37. ASTM International. Standard Test Method for Softening Point of Bitumen (Ring-and-Ball Apparatus); ASTM International: West Conshohocken, PA, USA, 2020; Volume ASTM D6/D36M-20.

38. ASTM International. Standard Test Method for Determining the Rheological Properties of Asphalt Binder Using a Dynamic Shear Rheometer; ASTM International: West Conshohocken, PA, USA, 2015; Volume ASTM D7175-15.

39. ASTM International. Standard Practice for Determining the Continuous Grading Temperatures and Continuous Grades for PG Graded Asphalt Binders; ASTM International: West Conshohocken, PA, USA, 2016; Volume ASTM D7643-16.

40. Saowapark, W.; Jubsilp, C.; Rimdusit, S. Natural rubber latex-modified asphalts for pavement application: Effects of phosphoric acid and sulphur addition. Road Mater. Pavement Des. 2019, 20, 211-224. [CrossRef]

41. Brovelli, C.; Hilliou, L.; Hemar, Y.; Pais, J.; Pereira, P.; Crispino, M. Rheological characteristics of EVA modified bitumen and their correlations with bitumen concrete properties. Constr. Build. Mater. 2013, 48, 1202-1208. [CrossRef]

42. Xia, T.; Zhou, L.; Xu, J.; Qin, Y.; Chen, W.; Dai, J. Rheology and thermal stability of polymer modified bitumen with coexistence of amorphous phase and crystalline phase. Constr. Build. Mater. 2018, 178, 272-279. [CrossRef]

43. ASTM International. Standard Test Method for Viscosity Determination of Asphalt at Elevated Temperatures Using a Rotational Viscometer; ASTM International: West Conshohocken, PA, USA, 2015; Volume ASTM D4402-15.

44. ASTM International. Standard Practice for Determining the Separation Tendency of Polymer from Polymer-Modified Asphalt; ASTM International: West Conshohocken, PA, USA, 2020; Volume ASTM D7173-20.

45. Sengoz, B.; Topal, A.; Isikyakar, G. Morphology and image analysis of polymer modified bitumens. Constr. Build. Mater. 2009, 23, 1986-1992. [CrossRef]

46. Yu, X.; Burnham, N.A.; Granados-Focil, S.; Tao, M. Bitumen's microstructures are correlated with its bulk thermal and rheological properties. Fuel 2019, 254, 115509. [CrossRef]

47. Iwamoto, S.; Lee, S.-H.; Endo, T. Relationship between aspect ratio and suspension viscosity of wood cellulose nanofibers. Polym. J. 2013, 46, 73-76. [CrossRef]

48. Samthong, C.; Seemork, J.; Nobukawa, S.; Yamaguchi, M.; Praserthdam, P.; Somwangthanaroj, A. Morphology, structure, and properties of poly(lactic acid) microporous films containing poly(butylene terephthalate) fine fibers fabricated by biaxial stretching. J. Appl. Polym. Sci. 2015, 132, 41415. [CrossRef] 